\title{
Vitamin K and Kidney Transplantation
}

\author{
Maria Fusaro ${ }^{1,2, *(\mathbb{C})}$, Laura Cosmai ${ }^{3}$, Pieter Evenepoel ${ }^{4}$, Thomas L. Nickolas ${ }^{5}{ }^{(}$, \\ Angela M. Cheung ${ }^{6}$, Andrea Aghi ${ }^{7}$, Giovanni Tripepi ${ }^{8}$, Mario Plebani ${ }^{9}$, Giorgio Iervasi ${ }^{1}$, \\ Roberto Vettor ${ }^{2}$, Martina Zaninotto ${ }^{9}$, Maura Ravera ${ }^{10}$, Marina Foramitti ${ }^{11}$, Sandro Giannini ${ }^{7}$, \\ Stefania Sella ${ }^{7}$ and Maurizio Gallieni ${ }^{3,12}$ (D) \\ 1 National Research Council (CNR), Institute of Clinical Physiology (IFC), 56124 Pisa, Italy; iervasi@ifc.cnr.it \\ Department of Medicine, University of Padova, 35128 Padova, Italy; roberto.vettor@unipd.it \\ 3 Nephrology Unit, ASST Fatebenefratelli Sacco, 20157 Milano, Italy; lacos@iol.it (L.C.); \\ maurizio.gallieni@unimi.it (M.G.) \\ 4 Laboratory of Nephrology, Department of Immunology and Microbiology, B-3000 Leuven, Belgium; \\ pieter.evenepoel@uzleuven.be \\ 5 Division of Nephrology, Department of Medicine, Columbia University, New York City, NY 10032, USA; \\ tln2001@cumc.columbia.edu \\ 6 Department of Medicine, University of Toronto, Toronto, ON M5S, Canada; angela.cheung@uhn.ca \\ 7 Department of Medicine, Clinica Medica 1, University of Padua, 35128 Padova, PD, Italy; \\ andrea.aghi@gmail.com (A.A.); sandro.giannini@unipd.it (S.G.); stefania.sella@unipd.it (S.S.) \\ 8 CNR-IFC, Clinical Epidemiology of Renal Diseases and Hypertension, Ospedali Riuniti, \\ 89124 Reggio Calabria, Italy; gtripepi@ifc.cnr.it \\ 9 Laboratory Medicine Unit, Department of Medicine, University of Padua, 35128 Padova, Italy; \\ mario.plebani@unipd.it (M.P.); marti.zaninotto@libero.it (M.Z.) \\ 10 Policlinico San Martino, 16132 Genova, Italy; maura.ravera@hsanmartino.it \\ 11 Divisione di Nefrologia e Dialisi, Renal Department, ASST-Cremona, Largo Priori 1, 26100 Cremona, Italy; \\ m.foramitti@asst-cremona.it \\ 12 Department of Biomedical and Clinical Sciences 'Luigi Sacco', Università di Milano, 20157 Milano, Italy \\ * Correspondence: dante.lucia11@gmail.com
}

Received: 30 July 2020; Accepted: 1 September 2020; Published: 5 September 2020

check for updates

\begin{abstract}
The assessment of the vitamin $\mathrm{K}$ status and its effects on clinical outcomes in kidney transplantation (KT) patients has sparked interest, but it is still largely unfulfilled. In part, this is due to difficulties in laboratory measurements of vitamin $\mathrm{K}$, especially K2 vitamers. Vitamin $\mathrm{K}$ status is currently best assessed by measuring undercarboxylated vitamin-K-dependent proteins. The relative contribution of vitamin $\mathrm{K} 1$ and $\mathrm{K} 2$ to the health status of the general population and CKD (chronic kidney disease) patients, including KT patients, is also poorly studied. Through a complete and first review of the existing literature, we summarize the current knowledge of vitamin $\mathrm{K}$ pathophysiology and its potential role in preventing KT complications and improving organ survival. A specific focus is placed on cardiovascular complications, bone fractures, and the relationship between vitamin $\mathrm{K}$ and cancer. Vitamin K deficiency could determine adverse outcomes, and KT patients should be better studied for vitamin $\mathrm{K}$ assessment and modalities of effective therapeutic approaches.
\end{abstract}

Keywords: kidney; transplant; phylloquinone; menaquinone; vitamin K; osteoporosis; bone; fracture; cardiovascular disease; calcification; cancer

\section{Introduction}

Kidney transplantation (KT) has several significant benefits compared to dialysis treatment, such as a better quality of life, prolonged survival, and lower costs [1]. However, relevant clinical complications affect KT patients, including progressive decline in renal function [2,3], vascular calcifications (VCs) [4,5], 
and bone fractures $(\mathrm{BFs})[6,7]$, which associate with a decreased survival of the graft and an increased mortality [5,7]. Unfortunately, the request for KT is higher than organ donations; therefore, it is essential to preserve graft survival as much as possible. A new therapeutic approach could be explored, Vitamin K. The aim of this review was to summarize the current vitamin K knowledge for its potential role in preventing KT complications and improving organ survival.

\section{Vitamin K, a Family of Vitamers: Types, Status, and Vitamin-K-Dependent Proteins (VKDPs)}

The 2-methyl-1,4-naphthoquinone group is common in $\mathrm{K}$ vitamers, including three main forms-phylloquinone (PK or vitamin K1), which can be found mostly in green vegetables and fruits; menaquinones (MKs or vitamin K2), classified conforming to the length of their unsaturated side chains (MK-4 to MK-15) [4]; and menadione (vitamin K3), a synthetic form. In humans, the most common K2 vitamer is MK-4, with the shortest chain, which is the only one produced by a systemic conversion from phylloquinone to menaquinones [8,9]. Intestinal bacteria synthesize vitamers MK-7 through MK-10. Additionally, they are also contained in meat, cheese, and fermented soy derivatives that use Bacillus Subtilis Natto, a traditional Japanese food (natto mainly contains MK7, and in smaller quantities, it contains MK8 and PK) [8,10]. Vitamin $\mathrm{K}$ is recycled continuously because there are very few vitamin K reserves [8].

Recommendations for daily intake of vitamin $\mathrm{K}$ are different in various countries because the data in the literature are scarce. In particular, in the United States, the Institute of Medicine has proposed an adequate intake (AI) for men and women of 120 and $90 \mu \mathrm{g} /$ day, respectively. The Italian LARN (Reference Levels of Assumption of nutrients and energy) [11], has proposed a higher intake, stratified by age -140 or $170 \mu \mathrm{g} /$ day for $18-59$ and $>60$ years old, respectively. Furthermore, in 2016, the Belgian health authority (Conseil Supérieur de la Santé) issued a statement indicating a recommended daily intake of 50-70 $\mu \mathrm{g} /$ day of vitamin $\mathrm{K} 1$ for the adult population and a new increased maximal tolerable intake of vitamin $\mathrm{K}$ of $1 \mathrm{mg} /$ day $(0.017 \mu \mathrm{g} / \mathrm{kg} /$ day $)$ [12]. Thus, a consensus on the definition of adequate intake for vitamin $\mathrm{K}$ does not exist, also because the contribution of the amount produced by intestinal bacteria remains uncertain. The absence of abnormal bleeding (an indication of physiological functioning of carboxylated coagulation factors) cannot be considered an estimate of adequate vitamin $\mathrm{K}$ levels, since it does not warrant vascular and bone health.

More than 15 types of vitamin-K-Dependent Proteins (VKDPs) were identified until now. The most studied VKDPs are the following-several proteins affecting coagulation (protein C, S, M, Z, factors VII, IX, X, and prothrombin), bone Gla protein (BGP, or osteocalcin), matrix Gla protein (MGP), Gas6 (Growth Arrest-Specific 6 Protein), GRP (Gla Rich Protein), and periostin [13]. Vitamin K acts at least in two ways. First, as the coenzyme of a carboxylase, determining the carboxylation of glutamic acid residues with a resulting formation of the amino acid $\gamma$-carboxy-glutamic acid (Gla: active form) [13,14]. Second, as a ligand of the steroid and xenobiotic receptor (SXR) and pregnane $X$ receptor (PXR, murine ortholog) [15]. SXR is a nuclear receptor involved in the transcriptional regulation of enzymes, such as cytochrome P450. Beyond being an inducer of detoxification and drug excretion genes, this receptor is expressed in osteoblasts and involved in bone metabolism $[9,16]$. Accordingly, PXR knockout mice develop an osteopenic phenotype [16].

Direct measurement of vitamers should be the ideal way to assess vitamin K status. However, to date, the standardization of the method is a great challenge. Obstacles are represented by lower physiological levels among fat-soluble vitamins and triglyceride interference, especially in chronic kidney disease (CKD) patients. Additionally, most studies only evaluated the PK levels (Table 1) $[17,18]$. On the other hand, the vitamin K status could be evaluated indirectly by the amount of undercarboxylated VKDPs (Table 1) [19-21]. 
Table 1. Levels of molecules defining vitamin K deficiency.

\begin{tabular}{ccc}
\hline Molecule & Direct Measurement & Indirect Measurement \\
\hline PK & General population: $<0.3 \mathrm{nmol} / \mathrm{L}[17]$ & $/$ \\
MKs & CKD patients $<0.4 \mathrm{nmol} / \mathrm{L}[18]$ & $/$ \\
PIVKA & Uncertain & $>2 \mathrm{nmol} / \mathrm{L}[19]$ \\
ucBGP & $/$ & $>20 \%$ or $\geq 4.5 \mathrm{ng} / \mathrm{mL}[19,20]$ \\
dp-ucMGP & $/$ & $>500 \mathrm{pmol} / \mathrm{L}[21]$ \\
\hline
\end{tabular}

Abbreviations: PK-phylloquinone; MKs-menaquinones; PIVKA—protein induced by vitamin $\mathrm{K}$ absence; ucBGP — undercarboxylated BGP; and dp-ucMGP—-dephosphorylated-undercarboxylated MGP. CKD: chronic kidney disease.

Several factors can influence vitamin K status in CKD patients, either reducing or enhancing its activity (Table 2). Among the causes of vitamin K deficiency in CKD patients, the following are more common-dietary restrictions determining inadequate intake; dysbiosis due to the uremic condition that leads to a decreased vitamin K (especially long-chain MKs); production by microbiota; and hemodialysis associated deficits $[8,22,23]$. Treatment of mineral bone disease (MBD) in CKD can also reduce vitamin K and VKDPs' actions. Some phosphate binders, such as sevelamer, bind fat-soluble vitamins, including vitamin $\mathrm{K}$. Its use is associated with higher dp-ucMGP levels in KT patients [24]. In the VItamin K Italian (VIKI) study, a cross-sectional study of 387 hemodialysis patients, we established the prevalence of vitamin $\mathrm{K}$ deficiency. Additionally, we assessed the relationship between vitamin $\mathrm{K}$ status, vertebral fractures (VFs), and vascular calcifications (VCs). MK4 deficiency was the strongest predictor of aortic calcification (OR, 2.82; 95\% CI, 1.14-7.01) [25]. In multivariable logistic regression, the odds ratio of MK4 deficiency in patients treated with sevelamer was $2.64,(95 \% \mathrm{CI}$ : $1.25-5.58, p=0.01$ ) [26]. Furthermore, warfarin use interferes with vitamin K recycling, reducing $\gamma$-carboxylation, and consequently, the activity of VKDPs. Thus, warfarin-treated patients develop vitamin K deficiency, associated with a high prevalence of VCs, VFs (in males), and mortality, both in the general population $[27,28]$ and in CKD patients $[29,30]$.

Table 2. Factors affecting vitamin $\mathrm{K}$ status in chronic kidney disease (CKD) patients.

\begin{tabular}{cc}
\hline Increase in VKDPs Activity & Decrease in VKDPs Activity \\
\hline Calcimimetics use [31] & Poor vitamin K intake [22] \\
Vitamin D analogs use [31] & Dysbiosis due to the uremic condition [7] \\
MMF use [5,32] & Hemodialysis treatment [23] \\
Kidney transplantation [33] & Sevelamer use [24,26] \\
& Warfarin use [25] \\
\hline
\end{tabular}

VKDPs: Vitamin-K-Dependent Proteins, MMF: mycophenolate mofetil.

On the other hand, in a secondary analysis of the VIKI study, we found that calcimimetics and vitamin $\mathrm{D}$ analogs might play a role in preserving VKDPs activity. We found an increase in total BGP levels and, only in patients treated with calcimimetics, the total MGP levels increased [31]. Furthermore, Keyzer et al. showed in $518 \mathrm{KT}$ recipients with 6-year follow-up of an inverse association between dp-ucMGP levels and mycophenolate mofetil (MMF) use [5], confirming a previous finding of an association between thoracic aorta calcification and shorter time on MMF treatment [32]. A recent prospective study of 34 patients assessed changes in VKDPs during the 1st year of KT, showing a decrease in the undercarboxylated (inactive form) amount [33].

\subsection{Vitamin K and Cardiovascular Disease in Kidney Transplantation}

Cardiovascular disease, strongly associated with vascular calcification, is the leading cause of death in end-stage kidney disease. Vascular calcification is inhibited by the vitamin-K-dependent protein MGP (matrix $\gamma$-carboxy-glutamic acid protein), which requires serine phosphorylation for its 
activation, beyond the gamma-carboxylation [13] (Figure 1). Thus, assessing the role of vitamin K in the complex setting of KT is of interest. Vascular calcifications, which can be linked to abnormalities in vitamin K status, are potential factors affecting cardiovascular health in transplanted patients.

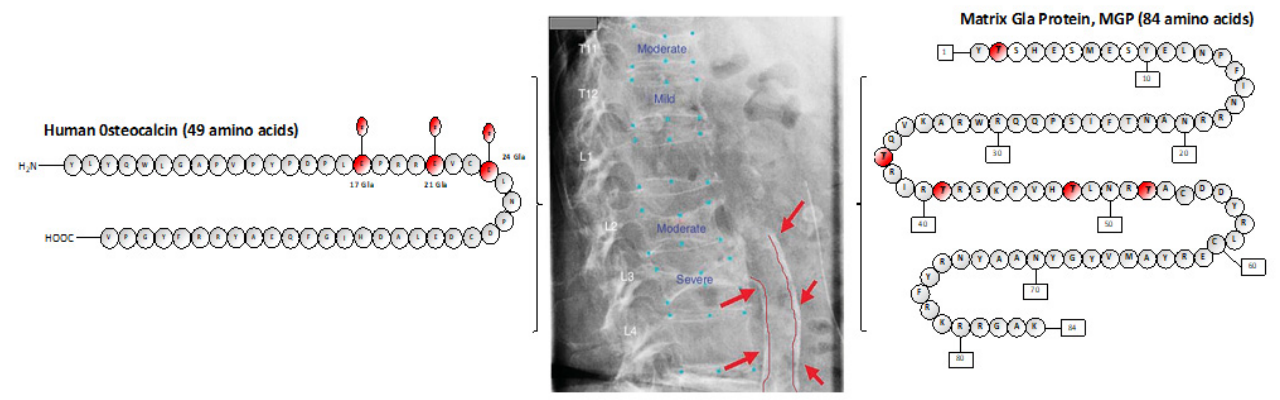

Figure 1. The two better-studied vitamin-K-dependent proteins, bone Gla protein (BGP, osteocalcin) and matrix Gla protein (MGP), contribute to cardiovascular and bone health in the general population and kidney transplant patients, who have an increased risk of cardiovascular events and bone fractures. Aortic calcifications and vertebral fractures are typical complications seen in CKD patients.

Jansz et al. [24] measured plasma dp-ucMGP, a marker reflecting low vitamin $\mathrm{K}$ status, in a cross-sectional study of 113 dialysis and $36 \mathrm{KT}$ patients. Dp-ucMGP levels were significantly lower in KT recipients (median 689 pmol/L), compared to patients on dialysis (median $1537 \mathrm{pmol} / \mathrm{L}$, $p<0.001$ ) [24]. These results suggest an improved vitamin K status after KT, which might lower the risk of developing vascular calcification. Preliminary data from Fusaro et al. [33] confirmed that serum concentrations of inactive vitamin-K-dependent proteins decrease 1-year post kidney transplantation, including dp-ucMGP (median pre-KT 910 pmol/L, post-KT 637 pmol/L, $p<0.001$ ). The prevalence of vitamin K deficiency, defined by the cut-off level of uc-BGP $>4.5 \mathrm{ng} / \mathrm{mL}$, decreased from $76.5 \%$ to $32.4 \%$ after KT.

Lees et al. [34] performed a meta-analysis of studies investigating vitamin K status, supplementation, and vascular disease. Specifically, they studied the effect of vitamin K supplementation on vascular stiffness and vascular calcification, as well as the association of inactive VKDP levels with incident cardiovascular disease and mortality. Combining data in different patient populations from 13 controlled clinical trials and 14 longitudinal studies (with substantial heterogeneity), supplementation with vitamin K significantly reduced vascular calcification, but not stiffness. Additionally, inactive VKDP levels (dp-ucMGP and ucBGP, indicating a vitamin K deficiency status) were associated with the combined endpoint of cardiovascular diseases or mortality.

Another meta-analysis, including 21 studies on different population cohorts totaling over 200,000 patients [35], pointed out an association of vitamin K with cardiovascular events and all-cause mortality. Higher dietary vitamin K consumption was associated with a significantly lower risk of coronary artery disease. For vitamin K1, the risk reduction was 8\% (HR 0.92, 95\% CI 0.84-0.99), and for vitamin $\mathrm{K} 2$, risk reduction was 30\% (HR 0.70, 95\% CI 0.53-0.93). Higher levels of dp-ucMGP were associated with increased risks (pooled HR 1.84) of all-cause and cardiovascular mortality, although the analysis could not establish causal relations.

Focusing on the KT population, Mansour et al. [36] investigated the association between the change in vitamin $\mathrm{K}$ status and indices of arterial stiffness in 60 patients, following eight weeks of menaquinone-7 (vitamin K2) supplementation (360 $\mu \mathrm{g}$ once daily). They found that 53\% of patients had a subclinical vitamin K deficiency. Menaquinone-7 supplementation reduced the mean dp-ucMGP concentrations by 55\% and the prevalence of subclinical vitamin K deficiency by $40 \%$. In addition, an improvement in arterial stiffness was independently associated with the reduction in dp-ucMGP concentration.

Data on the association between vitamin K status and mortality after KT were also available from a single-center observational study in 518 patients [5]. Most patients (91\%) had vitamin K 
insufficiency, defined by serum dp-ucMGP levels $>500 \mathrm{pmol} / \mathrm{L}$. Patients in the highest quartile of dp-ucMGP had a higher mortality risk than patients in the lowest quartile (HR, 3.10; 95\% CI, 1.87-5.12). This observational study indicated the opportunity of a randomized trial investigating whether vitamin K supplementation might lead to improved outcomes after KT [5]. Accordingly, the same group is now conducting a study [37] in KT recipients with vitamin K deficiency, whose main objective is to investigate the effect of vitamin K2 supplementation on serum calcification propensity. Calcification propensity is a surrogate marker, assessing the tendency to develop future vascular calcifications. The patient's serum is challenged with supersaturated calcium and phosphate solutions, which leads to the formation of primary calciprotein particles (CPPs). Such particles are then transformed into secondary CPPs with different timing, depending on the balance between calcification promoters and inhibitors. Secondary endpoints of the study include changes from the baseline in dp-ucMGP levels and vascular stiffness.

In a study aimed at assessing the prevalence and determinants of vascular calcifications in 281 renal transplant recipients, Nguyen et al. [32] found, among the determinants of aortic calcification, a role for a shorter exposure to mycophenolate mofetil and the current use of warfarin. Interestingly, Boxma et al. [38] found that dp-ucMGP levels were higher in patients on calcineurin inhibitors (855 (590-1350) pmol/L), indicating vitamin K deficiency, and were lower in patients on mycophenolate mofetil (591 (479-897) pmol/L). Thus, the protective effects of mycophenolate mofetil against vascular calcification [32] might be at least in part mediated by a favorable effect on vitamin K metabolism.

Preliminary data of a randomized, double-blind, placebo-controlled trial of vitamin $\mathrm{K}$ supplementation to improve vascular health in a small and heterogeneous cohort of 90 prevalent kidney transplant recipients, were recently presented and published in abstract form [39]. Patients were treated with vitamin $\mathrm{K}$ (menadiol diphosphate $5 \mathrm{mg}$ ) or placebo, thrice weekly for one year. The primary outcome was between-group differences in vascular stiffness at one year. Coronary calcifications were among the secondary outcomes. Vitamin K supplementation did not reduce vascular stiffness or calcification over one year. Future studies should consider larger sample sizes, higher doses, and a different combination of vitamin $\mathrm{K} 1$ and $\mathrm{K} 2$, considering that menadiol diphosphate, used in this study, is a synthetic form of vitamin $\mathrm{K}$, which might act differently from vitamin $\mathrm{K} 1$ and $\mathrm{K} 2$ on vascular health.

Table 3 summarizes the main studies $[4,5,7,24,36,38]$ that evaluated the vitamin $\mathrm{K}$ status in organ transplantation. Another study in lung and heart transplantation demonstrated that bone status improved in patients with low vitamin K2 levels, after dietary supplementation [40].

Table 3. Vitamin K status in kidney transplantation studies.

\begin{tabular}{cccc}
\hline Author, Year & Patient Number & $\begin{array}{c}\text { \% of Patients with } \\
\text { Vitamin K Deficiency }\end{array}$ & VKDP Measured \\
\hline Boxma, 2012 [38] & 60 & $80 \%$ & dp-ucMGP \\
Keyzer, 2015 [5] & 518 & $91 \%$ & dp-ucMGP \\
Mansour, 2017 [36] & 60 & $53.3 \%$ & dp-ucMGP \\
Jansz, 2018 [24] & 32 & $62 \%$. & dp-ucMGP \\
Evenepoel, 2019 [7] & 468 & $90 \%$ & dp-ucMGP \\
van Ballegooijen, 2020 [4] & 461 & $50 \%$ & dp-ucMGP \\
\hline
\end{tabular}

VKDP: Vitamin-K-Dependent Proteins, dp-ucMGP: dephosphorylated-undercarboxylated MGP.

\subsection{Vitamin K and Bone Fractures in Kidney Transplantation}

Bone fractures $(\mathrm{BFs})$ are relevant MBD complications among CKD patients. In particular, hip fractures are four times more common than the general population [41,42]. In KT patients, there is a 30\% increase of BFs in the first three years after transplantation [7].

Vitamin K can influence bone health in different ways. First, carboxylation of glutamine residues at 17, 21, and 24 of bone Gla protein (carboxylated BGP:cBGP, active form) allows its binding to bone hydroxyapatite, so that $\mathrm{CBGP}$ can exercise both an inhibition of bone mineralization and 
the regulation of the rate of mineral maturation [43]. Accordingly, BGP knockout mice develop hyperostosis [44]. Second, vitamin K2 (vitamin K1 is not capable of activating SXR until after its conversion into MK-4) acting as a ligand of SXR/PXR induce the transcription of several genes relevant to mineral metabolism - genes encoding bone collagen proteins (Tsukushi, Matrilin-2, primary SXR target genes) affecting bone quality, and genes regulating osteoblastogenesis, osteoclastogenesis (CD14), and osteoblast differentiation (Msx2) [16,45] (Figure 1).

Furthermore, beyond the well-known protective effects of MGP in vascular calcification, a recent study [46] highlighted its role in skeletal health, indicating that MGP overexpression suppresses osteoclast differentiation and bone resorption. In fact, the expression of the Nuclear Factor of Activated T cells, cytoplasmic 1 (NFATc1), which is the leading player in osteoclastogenesis, is controlled by MGP [46-48]. These experimental data were supported by the clinical results obtained in 468 de novo renal transplant recipients [7]. In this cohort, Cox proportional hazards analysis found that a dp-ucMGP above the median $(1150 \mathrm{nmol} / \mathrm{L}$, and notably 421 patients had levels $>500 \mathrm{nmol} / \mathrm{L}$, indicating a condition of vitamin $\mathrm{K}$ deficiency) was associated with incident fractures (HR 2.21, $p<0.05$ ). Moreover, high dp-ucMGP levels were independently associated with elevated inflammatory markers and low BMD [7].

Several studies showed a relationship between low vitamin $\mathrm{K}$ intake or low vitamin $\mathrm{K}$ levels, and fracture risk in the general population. In the VIKI study [25], we highlighted that Vitamin K1 deficiency was the strongest predictor of vertebral fractures (VFs) (OR: 2.94, $p=0.0053$ ) in $387 \mathrm{HD}$ patients. Cheung et al. confirmed our findings in a study of 440 postmenopausal women. They gave $5 \mathrm{mg}$ of vitamin K1 daily for two years, showing a reduction of the risk of VFs (HR 0.45, $p=0.04$ ), despite a lack of effects on BMD and bone resorption, sustaining the hypothesis of a potential role of vitamin K in preserving bone quality [49]. Furthermore, Menatetrenone or MK-4 was approved as a drug for the treatment of osteoporosis in Japan in 1960. Indeed interventional studies with MK-4 ( $45 \mathrm{mg} /$ day orally) demonstrated both a reduction of the incidence of bone fractures and improvements of BMD [50].

\subsection{Vitamin K and Cancer in Kidney Transplantation}

After cardiovascular diseases, cancer is the second most common cause of mortality and morbidity in KT recipients, showing at least a twofold higher risk of developing cancer or dying from cancer than the general population. The increased cancer risk in transplant recipients is multifactorial and is attributed to oncogenic viruses, immunosuppression, altered $\mathrm{T}$ cell immunity, or a combination of the above [51]. The standardized incidence ratios (SIRs) for infection-related malignancies-i.e., Epstein-Barr virus (EBV)-associated lymphoma, Kaposi sarcoma (KS), hepatocellular carcinoma, genital, and gastric cancers-are significantly elevated in kidney transplant recipients. However, a number of other cancer types unrelated to infection are also more common in the transplanted population, including squamous cell cancers of the skin and lip, renal cell carcinoma (RCC), cholangiocarcinoma, and salivary gland cancer. Moreover, the incidence of lung and colorectal cancer is even higher in the transplant population. In contrast, the SIR of prostate and breast cancer is not higher in transplant recipients compared to the general population [52].

There are no studies correlating the vitamin K nutritional status in KT patients with the incidence of post-transplant cancers. However, it is reasonable to think that the vitamin $\mathrm{K}$ status might also be involved in the development of cancer, as an additional risk factor, because abnormalities of several VKDPs are related to cancer.

\subsection{Growth Arrest-Specific Protein 6 (Gas6)}

Gas6 is a human gene encoding the Gas6 protein, present in several tissues (e.g., vascular endothelium, kidney, heart, and the bone marrow) and is upregulated in growth-arrested fibroblasts [13]. Gas6 shows the highest affinity for Axl, followed by Tyro3 and then for Mer (TAM) receptors, leading to the activation of downstream signaling, such as phosphatidylinositol 3-kinase (PI3K), extracellular 
signal-regulated kinase (ERK), and nuclear factor kappa-light-chain-enhancer of activated B cells (NF-kB) pathways. Thus, it is involved in the stimulation of cell proliferation, migration, differentiation, adhesion, and apoptosis [53].

Upregulation of Gas/TAM can promote the development of several cancers, and clinically the expression of Gas6 and TAM receptors predicts a poor prognosis. Specifically, Gas6 is overexpressed in melanoma, schwannoma, glioma, and pancreatic ductal adenocarcinoma cell lines, and it is upregulated in ovarian cancer and thyroid cancer specimens [54]. Furthermore, one study showed that Gas6 is amplified in breast cancer, and human prostate cancer cell lines were found to grow significantly better in vertebral bodies transplanted from Gas6-/- animals than in those derived from Gas6 +/+ animals $[55,56]$.

Gas6 is also highly expressed in bladder cancer. It is significantly associated with tumor grade, T stage, and worse prognosis. GAS6 might play a pivotal role in the development of bladder cancer, being a potential target for its treatment [57].

\subsection{Periostin}

Similar to other VKDPs, the carboxylation of periostin is dependent on vitamin K. Periostin is an extracellular matrix protein that binds integrins, leading to stimulation of cellular adhesion and migration [58].

The tumor microenvironment is highly complex, and consists of non-tumor cells, extracellular matrix proteins (matricellular proteins), and soluble factors, modulating the immune response against tumor cells [59].

Periostin is a matricellular protein, and excessive periostin deposition plays a pivotal role in cancer cell proliferation, invasion, and dissemination [60]. In breast cancer, periostin is expressed in invasive ductal carcinoma cells [61], and it might play a role in cancer progression [62]. Periostin could be a marker of breast cancer metastasis [63]. Finally, periostin could predict prognosis in patients with breast cancer. In breast cancer patients who underwent surgery and radiation therapy, local recurrence-free survival, distant metastasis-free survival, and overall survival were significantly lower in the patients whose tumors expressed periostin [64].

Serum periostin levels were significantly higher in patients with colorectal cancer (CRC) than in healthy controls and were associated with clinical stages. Patients with lower serum periostin had better survival than those with high serum periostin [65]. A study of resected hepatocellular carcinoma (HCC) specimens showed that high periostin levels were more frequent in cases of multiple tumors, presence of microvascular invasion, and advanced-stage disease. Furthermore, patients with high periostin expression had significantly lower overall survival rates than those with low periostin expression [66]. As a whole, periostin is highly expressed in a large number of cancers, and this association confers a worse prognosis to patients, as shown in Table 4.

Table 4. Periostin overexpression and cancer prognosis.

\begin{tabular}{ccc}
\hline Site of Expression & Cancer & Cancer Outcome \\
\hline & Prostate cancer [67] & \\
& Lung cancer [68] & Poor prognosis \\
& Colorectal cancer [69] & Reduced OS \\
Stroma & Breast cancer [62] & Reduced PFS \\
& Bladder cancer [70] & Advanced stage and metastasis \\
& Hepatocellular cancer [71] & \\
& Pancreatic cancer [59] & \\
& Ovarian cancer [59] & \\
\hline
\end{tabular}


Table 4. Cont.

\begin{tabular}{ccc}
\hline Site of Expression & Cancer & Cancer Outcome \\
\hline Cancer epithelial cells & $\begin{array}{c}\text { Colorectal cancer [69] } \\
\text { Breast cancer [63] } \\
\text { Hepatocellular cancer [71] } \\
\text { Pancreatic cancer [59] } \\
\text { Ovarian cancer [59] }\end{array}$ & $\begin{array}{c}\text { Reduced OS } \\
\text { Reduced PFS } \\
\text { Tumor grade (poor prognosis) } \\
\text { Increased microvascular invasion } \\
\text { (poor prognosis) } \\
\text { Advanced stages and cancer } \\
\text { recurrence }\end{array}$ \\
\hline Cancer-associated fibroblast & Breast cancer [62] & $\begin{array}{c}\text { Reduced OS } \\
\text { Reduced PFS }\end{array}$ \\
\hline Extracellular vesicles & Bladder Cancer [70] & Tumor stage (poor prognosis) \\
\hline Tumor & Osteosarcoma [59] & Reduced OS \\
Reduced PFS
\end{tabular}

OS—Overall Survival; PFS—Progression Free Survival.

\subsection{Vitamin K Administration in Cancer Prevention and Treatment}

Several VKDPs are involved in cancer development. Vitamin K2 administration in vivo inhibits the cellular proliferation of several types of cancers [72,73]. Many studies investigated the role of vitamin K intake and supplementation in the prevention of cancer development, progression, and recurrence [74].

The European Prospective Investigation into Cancer and Nutrition Heidelberg cohort study, which included 24,340 cancer-free participants followed up for ten years, found a significant inverse association between vitamin $\mathrm{K} 2$ intake and cancer mortality, but not cancer incidence [75]. However, a significant inverse relationship between cancer incidence and Vitamin K2 intake was demonstrated in men [75]. In the Prevención con Dieta Mediterránea study (PREDIMED), with a median follow-up of 4.8 years, the dietary intake of both vitamin K1 and K2 was associated with a decreased cancer incidence [76]. Notably, vitamin K intake was substantially higher than that in the Heidelberg cohort [76].

Vitamin K2 supplementation in patients who underwent curative hepatectomy or radiofrequency ablation for HCC, reduced HCC recurrence, although not significantly [77,78]. Additionally, $45 \mathrm{mg}$ per day of vitamin K2 supplementation resulted in a significantly lower risk of HCC development in women with viral cirrhosis [79], suggesting that vitamin K2 might play a role in preventing the development of HCC in high-risk patients [79].

As a whole, the association of Vitamin $\mathrm{K}$ with cancer is still under investigation, the research suggests that vitamin $\mathrm{K}$ is involved in anti-tumor responses through several mechanisms. Whether a suboptimal vitamin $\mathrm{K}$ status contributes to cancer development is not yet established; further studies will hopefully define the role of vitamin $\mathrm{K}$, especially in transplanted patients.

\section{Conclusions}

After kidney transplantation, vitamin $\mathrm{K}$ status improves compared to patients remaining in dialysis care, and the progression of calcification slows down. However, because bone fractures and vascular calcifications remain a significant cause of morbidity and mortality in kidney transplant recipients, more evidence is undoubtedly needed on the effects of vitamin $\mathrm{K}$ supplementation at physiologic and pharmacologic doses of different vitamers of the vitamin $\mathrm{K}$ family.

Author Contributions: All authors have contributed, read and agreed to the published version of the manuscript.

Funding: This review was prepared without external funding.

Conflicts of Interest: The authors declare no conflict of interest. 


\section{References}

1. Lorent, M.; Foucher, Y.; Kerleau, K.; Brouard, S.; Baayen, C.; Lebouter, S.; Naesens, M.; Bestard Matamoros, O.; Åsberg, A.; Giral, M. The EKiTE network (epidemiology in kidney transplantation-A European validated database): An initiative epidemiological and translational European collaborative research. BMC Nephrol. 2019, 20, 365. [CrossRef] [PubMed]

2. Savoj, J.; Becerra, B.; Kim, J.K.; Fusaro, M.; Gallieni, M.; Lombardo, D.; Lau, W.L. Utility of cardiac biomarkers in the setting of kidney disease. Nephron 2019, 141, 227-235. [CrossRef] [PubMed]

3. Wei, F.-F.; Trenson, S.; Thijs, L.; Huang, Q.-F.; Zhang, Z.-Y.; Yang, W.; Moliterno, P.; Allegaert, K.; Boggia, J.; Janssens, S.; et al. Desphospho-uncarboxylated matrix Gla protein is a novel circulating biomarker predicting deterioration of renal function in the general population. Nephrol. Dial. Transplant. 2018, 33, 1122-1128. [CrossRef] [PubMed]

4. Van Ballegooijen, A.J.; Beulens, J.W.J.; Keyzer, C.A.; Navis, G.J.; Berger, S.P.; De Borst, M.H.; Vervloet, M.G.; Bakker, S.J.L. Joint association of vitamins $\mathrm{D}$ and $\mathrm{K}$ status with long-term outcomes in stable kidney transplant recipients. Nephrol. Dial. Transplant. 2020, 35, 706-714. [CrossRef]

5. Keyzer, C.A.; Vermeer, C.; Joosten, M.M.; Knapen, M.H.; Drummen, N.E.; Navis, G.; Bakker, S.J.; De Borst, M.H. Vitamin K status and mortality after kidney transplantation: A cohort study. Am. J. Kidney Dis. 2015, 65, 474-483. [CrossRef] [PubMed]

6. Ball, A.M.; Gillen, D.L.; Sherrard, D.; Weiss, N.S.; Emerson, S.S.; Seliger, S.L.; Kestenbaum, B.R.; Stehman-Breen, C. Risk of hip fracture among dialysis and renal transplant recipients. JAMA 2002, 288, 3014-3018. [CrossRef]

7. Evenepoel, P.; Claes, K.; Meijers, B.; Laurent, M.R.; Bammens, B.; Naesens, M.; Sprangers, B.; Pottel, H.; Cavalier, E.; Kuypers, D. Poor vitamin K Status is associated with low bone mineral density and increased fracture risk in end-stage renal disease. J. Bone Miner. Res. 2019, 34, 262-269. [CrossRef]

8. Shearer, M.J.; Newman, P. Metabolism and cell biology of vitamin K. Thromb. Haemost. 2008, 100, 530-547. [CrossRef]

9. Fusaro, M.; Gallieni, M.; Rizzo, M.A.; Stucchi, A.; Delanaye, P.; Cavalier, E.; Moyses, R.M.; Jorgetti, V.; Iervasi, G.; Giannini, S.; et al. Vitamin K plasma levels determination in human health. Clin. Chem. Lab. Med. 2017, 55, 789-799. [CrossRef]

10. Booth, S.L. Vitamin K: Food composition and dietary intakes. Food Nutr. Res. 2012, 56, 5505. [CrossRef]

11. Società Italiana di Nutrizione Umana-SINU. Livelli di Assunzione di Riferimento di Nutrienti ed Energia per la Popolazione Italiana, (LARN) Revisione 2014; SICS: Roma, Italy, 2014.

12. Conseil Supérieur de la Santé. Recommandations nutritionnelles pour la Belgique-CSS n 9285; Conseil Supérieur de la Santé: Brussels, Belgium, 2016; pp. 160-164. Available online: https://www.health.belgium.be/ sites/default/files/uploads/fields/fpshealth_theme_file/9285_avis_rec_nutr_corr_170105_0.pdf (accessed on 3 September 2020).

13. Fusaro, M.; Gallieni, M.; Porta, C.; Nickolas, T.L.; Khairallah, P. Vitamin K effects in human health: New insights beyond bone and cardiovascular health. J. Nephrol. 2020, 33, 239-249. [CrossRef] [PubMed]

14. Silaghi, C.N.; Ilyés, T.; Filip, V.P.; Farcaș, M.; Van Ballegooijen, A.J.; Crăciun, A.M. Vitamin K dependent proteins in kidney disease. Int. J. Mol. Sci. 2019, 20, 1571. [CrossRef] [PubMed]

15. Fusaro, M.; Mereu, M.C.; Aghi, A.; Iervasi, G.; Gallieni, M. Vitamin K and bone. Clin. Cases Miner. Bone Metab. 2017, 14, 200-206. [CrossRef]

16. Azuma, K.; Casey, S.C.; Urano, T.; Horie-Inoue, K.; Ouchi, Y.; Blumberg, B.; Inoue, S. Pregnane X receptor knockout mice display aging-dependent wearing of articular cartilage. PLoS ONE 2015, 10, e0119177. [CrossRef] [PubMed]

17. Sadowski, J.A.; Hood, S.J.; Dallal, G.E.; Garry, P.J. Phylloquinone in plasma from elderly and young adults: Factors influencing its concentration. Am. J. Clin. Nutr. 1989, 50, 100-108. [CrossRef] [PubMed]

18. Pilkey, R.M.; Morton, A.R.; Boffa, M.B.; Noordhof, C.; Day, A.G.; Su, Y.; Miller, L.M.; Koschinsky, M.L.; Booth, S.L. Subclinical vitamin K deficiency in hemodialysis patients. Am. J. Kidney Dis. 2007, 49, 432-439. [CrossRef] [PubMed]

19. McCabe, K.M.; Adams, M.A.; Holden, R.M. Vitamin K status in chronic kidney disease. Nutrients 2013, 5, 4390-4398. [CrossRef] [PubMed] 
20. Kuwabara, A.; Tanaka, K.; Tsugawa, N.; Nakase, H.; Tsuji, H.; Shide, K.; Kamao, M.; Chiba, T.; Inagaki, N.; Okano, T.; et al. High prevalence of vitamin $\mathrm{K}$ and D deficiency and decreased BMD in inflammatory bowel disease. Osteoporos. Int. 2009, 20, 935-942. [CrossRef] [PubMed]

21. Riphagen, I.J.; van der Molen, J.C.; Van Faassen, M.H.J.R.; Navis, G.; De Borst, M.H.; Muskiet, F.A.J.; de Jong, W.H.; Bakker, S.J.; Kema, I.P. Measurement of plasma vitamin K1 (phylloquinone) and K2 (menaquinones-4 and -7) using HPLC-tandem mass spectrometry. Clin. Chem. Lab. Med. 2016, 54, 1201-1210. [CrossRef]

22. Fusaro, M.; D’Alessandro, C.; Noale, M.; Tripepi, G.; Plebani, M.; Veronese, N.; Iervasi, G.; Giannini, S.; Rossini, M.; Tarroni, G.; et al. Low vitamin K1 intake in haemodialysis patients. Clin. Nutr. 2017, 36, 601-607. [CrossRef]

23. Cranenburg, E.C.M.; Schurgers, L.J.; Uiterwijk, H.H.; Beulens, J.W.; Dalmeijer, G.W.; Westerhuis, R.; Magdeleyns, E.J.; Herfs, M.; Vermeer, C.; Laverman, G.D. Vitamin K intake and status are low in hemodialysis patients. Kidney Int. 2012, 82, 605-610. [CrossRef] [PubMed]

24. Jansz, T.T.; Neradova, A.; van Ballegooijen, A.J.; Verhaar, M.C.; Vervloet, M.G.; Schurgers, L.J.; van Jaarsveld, B.C. The role of kidney transplantation and phosphate binder use in vitamin $\mathrm{K}$ status. PLoS ONE 2018, 13, e0203157. [CrossRef] [PubMed]

25. Fusaro, M.; Noale, M.; Viola, V.; Galli, F.; Tripepi, G.; Vajente, N.; Plebani, M.; Zaninotto, M.; Guglielmi, G.; Miotto, D.; et al. Vitamin K, vertebral fractures, vascular calcifications, and mortality: VItamin K Italian (VIKI) dialysis study. J. Bone Miner. Res. 2012, 27, 2271-2278. [CrossRef] [PubMed]

26. Fusaro, M.; Aghi, A.; Khairallah, P.; Gallieni, M.; Cozzolino, M.G.; Russo, D.; Mereu, M.C.; Ravera, M.; Tripepi, G.L.; Nickolas, T. Sevelamer use is associated with decreased vitamin K levels in hemodialysis patients: Results from the Vitamin K Italian (VIKI) study. Abstract FR-PO146. J. Am. Soc. Nephrol. 2019, 30,471 .

27. Weijs, B.; Blaauw, Y.; Rennenberg, R.J.; Schurgers, L.J.; Timmermans, C.C.; Pison, L.; Nieuwlaat, R.; Hofstra, L.; Kroon, A.A.; Wildberger, J.; et al. Patients using vitamin K antagonists show increased levels of coronary calcification: An observational study in low-risk atrial fibrillation patients. Eur. Hear. J. 2011, 32, 2555-2562. [CrossRef]

28. Gage, B.F.; Birman-Deych, E.; Radford, M.J.; Nilasena, D.S.; Binder, E.F. Risk of osteoporotic fracture in elderly patients taking warfarin. Arch. Intern. Med. 2006, 166, 241-246. [CrossRef]

29. Fusaro, M.; Tripepi, G.; Noale, M.; Plebani, M.; Zaninotto, M.; Piccoli, A.; Naso, A.; Miozzo, D.; Giannini, S.; Avolio, M.; et al. Prevalence of vertebral fractures, vascular calcifications, and mortality in warfarin treated hemodialysis patients. Curr. Vasc. Pharmacol. 2015, 13, 248-258. [CrossRef]

30. Lin, M.C.; Streja, E.; SooHoo, M.; Hanna, M.; Savoj, J.; Kalantar-Zadeh, K.; Lau, W.L. Warfarin use and increased mortality in end-stage renal disease. Am. J. Nephrol. 2017, 46, 249-256. [CrossRef]

31. Fusaro, M.; Giannini, S.; Gallieni, M.; Noale, M.; Tripepi, G.; Rossini, M.; Messa, P.; Rigotti, P.; Pati, T.; Barbisoni, F.; et al. Calcimimetic and vitamin D analog use in hemodialyzed patients is associated with increased levels of vitamin $\mathrm{K}$ dependent proteins. Endocrine 2016, 51, 333-341. [CrossRef]

32. Nguyen, P.T.; Coche, E.; Goffin, E.; Beguin, C.; Vlassenbroek, A.; Devuyst, O.; Robert, A.; Jadoul, M. Prevalence and determinants of coronary and aortic calcifications assessed by chest CT in renal transplant recipients. Am. J. Nephrol. 2007, 27, 329-335. [CrossRef]

33. Fusaro, M.; Khairallah, P.; Aghi, A.; Plebani, M.; Zaninotto, M.; Cosma, C.; Farias, M.A.A.; Cortez, N.E.; Tripepi, G.L.; Nickolas, T. Vitamin K-dependent proteins after kidney transplantation: Results from a prospective study. Abstract FR-PO167. J. Am. Soc. Nephrol. 2019, 30, 477.

34. Lees, J.S.; Chapman, F.A.; Witham, M.D.; Jardine, A.G.; Mark, P.B. Vitamin K status, supplementation and vascular disease: A systematic review and meta-analysis. Heart 2018, 105, 938-945. [CrossRef] [PubMed]

35. Chen, H.-G.; Sheng, L.-T.; Zhang, Y.-B.; Cao, A.-L.; Lai, Y.-W.; Kunutsor, S.K.; Jiang, L.; Pan, A. Association of vitamin $\mathrm{K}$ with cardiovascular events and all-cause mortality: A systematic review and meta-analysis. Eur. J. Nutr. 2019, 58, 2191-2205. [CrossRef] [PubMed]

36. Mansour, A.; Hariri, E.; Daaboul, Y.; Korjian, S.; El Alam, A.; Protogerou, A.D.; Kilany, H.; Karam, A.; Stephan, A.; Bahous, S.A. Vitamin K2 supplementation and arterial stiffness among renal transplant recipients-A single-arm, single-center clinical trial. J. Am. Soc. Hypertens. 2017, 11, 589-597. [CrossRef] 
37. Keyzer, C.A. Placebo-controlled double-blind randomized controlled trial investigating vitamin K supplementation on vascular calcification propensity in vitamin $\mathrm{K}$ deficient renal transplant recipients. EudraCT Number: 2019-004906-88. Available online: https://www.clinicaltrialsregister.eu/ctr-search/trial/ 2019-004906-88/NL/ (accessed on 3 September 2020).

38. Boxma, P.Y.; Berg, E.V.D.; Geleijnse, J.M.; Laverman, G.D.; Schurgers, L.J.; Vermeer, C.; Kema, I.P.; Muskiet, F.A.; Navis, G.; Bakker, S.J.L.; et al. Vitamin K intake and plasma desphospho-uncarboxylated matrix Gla-protein levels in kidney transplant recipients. PLoS ONE 2012, 7, e47991. [CrossRef]

39. Witham, M.D.; Lees, J.S.; White, M.; Band, M.; Bell, S.; Chantler, D.J.; Ford, I.; Fulton, R.L.; Kennedy, G.; Littleford, R.C.; et al. Vitamin K supplementation to improve vascular stiffness in CKD: The K4Kidneys randomized controlled trial. J. Am. Soc. Nephrol. 2020. [CrossRef]

40. Førli, L.; Bollerslev, J.; Simonsen, S.; Isaksen, G.A.; Kvamsdal, K.E.; Godang, K.; Gadeholt, G.; Pripp, A.H.; Bjortuft, O. Dietary vitamin K2 supplement improves bone status after lung and heart transplantation. Transplantation 2010, 89, 458-464. [CrossRef]

41. Alem, A.M.; Sherrard, D.J.; Gillen, D.L.; Weiss, N.S.; Beresford, S.A.; Heckbert, S.R.; Wong, C.; Stehman-Breen, C. Increased risk of hip fracture among patients with end-stage renal disease. Kidney Int. 2000, 58, 396-399. [CrossRef]

42. Jadoul, M.; Albert, J.M.; Akiba, T.; Akizawa, T.; Arab, L.; Bragg-Gresham, J.; Mason, N.; Prutz, K.-G.; Young, E.; Pisoni, R. Incidence and risk factors for hip or other bone fractures among hemodialysis patients in the Dialysis Outcomes and Practice Patterns Study. Kidney Int. 2006, 70, 1358-1366. [CrossRef]

43. Nagata, Y.; Inaba, M.; Imanishi, Y.; Okazaki, H.; Yamada, S.; Mori, K.; Shoji, S.; Koyama, H.; Okuno, S. Increased undercarboxylated osteocalcin/intact osteocalcin ratio in patients undergoing hemodialysis. Osteoporos. Int. 2015, 26, 1053-1061. [CrossRef]

44. Ducy, P.; Desbois, C.; Boyce, B.; Pinero, G.; Story, B.; Dunstan, C.; Smith, E.; Bonadio, J.; Goldstein, S.; Gundberg, C.; et al. Increased bone formation in osteocalcin-deficient mice. Nature 1996, 382, 448-452. [CrossRef] [PubMed]

45. Hirota, Y.; Suhara, Y. New aspects of vitamin K research with synthetic ligands: Transcriptional activity via SXR and neural differentiation Activity. Int. J. Mol. Sci. 2019, 20, 3006. [CrossRef] [PubMed]

46. Zhang, Y.; Zhao, L.; Wang, N.; Li, J.; He, F.; Li, X.; Wu, S. Unexpected role of matrix Gla protein in osteoclasts: Inhibiting osteoclast differentiation and bone resorption. Mol. Cell. Boil. 2019, 39, e00012-19. [CrossRef] [PubMed]

47. Vassalle, C.; Mazzone, A. Bone loss and vascular calcification: A bi-directional interplay? Vasc. Pharmacol. 2016, 86, 77-86. [CrossRef] [PubMed]

48. Lu, X.; Gao, B.; Yasui, T.; Li, Y.; Liu, T.; Mao, X.; Hirose, M.; Wu, Y.; Yu, D.; Zhu, Q.; et al. Matrix Gla protein is involved in crystal formation in kidney of hyperoxaluric rats. Kidney Blood Press. Res. 2013, 37, 15-23. [CrossRef]

49. Cheung, A.M.; Tile, L.; Lee, Y.; Tomlinson, G.; Hawker, G.; Scher, J.; Hu, H.; Vieth, R.; Thompson, L.; Jamal, S.; et al. Vitamin K supplementation in postmenopausal women with osteopenia (ECKO Trial): A randomized controlled trial. PLoS Med. 2008, 5, e196. [CrossRef]

50. Mott, A.; Bradley, T.; Wright, K.; Cockayne, E.S.; Shearer, M.J.; Adamson, J.; Lanham-New, S.A.; Torgerson, D.J. Effect of vitamin $\mathrm{K}$ on bone mineral density and fractures in adults: An updated systematic review and meta-analysis of randomised controlled trials. Osteoporos. Int. 2019, 30, 1543-1559. [CrossRef]

51. Cohen-Bucay, A.; Gordon, C.E.; Francis, J.M. Non-immunological complications following kidney transplantation. F1000Research 2019, 8. [CrossRef]

52. Engels, E.A.; Pfeiffer, R.M.; Fraumeni, J.F.; Kasiske, B.L.; Israni, A.K.; Snyder, J.J.; Wolfe, R.A.; Goodrich, N.P.; Bayakly, A.R.; Clarke, C.A.; et al. Spectrum of cancer risk among US solid organ transplant recipients. JAMA 2011, 306, 1891-1901. [CrossRef]

53. Sasaki, T.; Knyazev, P.G.; Clout, N.J.; Cheburkin, Y.; Göhring, W.; Ullrich, A.; Timpl, R.; Hohenester, E. Structural basis for Gas6-Axl signalling. EMBO J. 2006, 25, 80-87. [CrossRef]

54. Buehler, M.; Tse, B.W.-C.; Leboucq, A.; Jacob, F.; Caduff, R.; Fink, D.; Goldstein, D.R.; Heinzelmann-Schwarz, V. Meta-analysis of microarray data identifies GAS6 expression as an independent predictor of poor survival in ovarian cancer. BioMed Res. Int. 2013, 2013, 238284. [CrossRef] [PubMed] 
55. Jung, Y.; Shiozawa, Y.; Wang, J.; McGregor, N.; Dai, J.; Park, S.I.; Berry, J.E.; Havens, A.M.; Joseph, J.; Kim, J.K.; et al. Prevalence of prostate cancer metastases after intravenous inoculation provides clues into the molecular basis of dormancy in the bone marrow microenvironment. Neoplasia 2012, 14, 429-439. [CrossRef] [PubMed]

56. Sainaghi, P.P.; Castello, L.; Bergamasco, L.; Galletti, M.; Bellosta, P.; Avanzi, G.C. Gas6 induces proliferation in prostate carcinoma cell lines expressing the Axl receptor. J. Cell. Physiol. 2005, 204, 36-44. [CrossRef] [PubMed]

57. Mao, S.; Wu, Y.; Wang, R.; Guo, Y.; Bi, D.; Ma, W.; Zhang, W.; Zhang, J.; Yan, Y.; Yao, X. Overexpression of GAS6 promotes cell proliferation and invasion in bladder cancer by activation of the PI3K/AKT pathway. OncoTargets Ther. 2020, 13, 4813-4824. [CrossRef]

58. Norris, R.A.; Damon, B.; Mironov, V.; Kasyanov, V.; Ramamurthi, A.; Moreno-Rodriguez, R.; Trusk, T.; Potts, J.D.; Goodwin, R.L.; Davis, J.; et al. Periostin regulates collagen fibrillogenesis and the biomechanical properties of connective tissues. J. Cell. Biochem. 2007, 101, 695-711. [CrossRef]

59. González-González, L.; Alonso, J. Periostin: A matricellular protein with multiple functions in cancer development and progression. Front. Oncol. 2018, 8, 225. [CrossRef]

60. Liu, Y.; Huang, Z.; Cui, D.; Ouyang, G. The multiaspect functions of periostin in tumor progression. Adv. Exp. Med. Biol. 2019, 1132, 125-136. [CrossRef]

61. Ratajczak-Wielgomas, K.; Grzegrzolka, J.; Piotrowska, A.; Matkowski, R.; Wojnar, A.; Rys, J.; Ugorski, M.; Dziegiel, P. Expression of periostin in breast cancer cells. Int. J. Oncol. 2017, 51, 1300-1310. [CrossRef]

62. Kim, G.-E.; Lee, J.S.; Park, M.H.; Yoon, J.H. Epithelial periostin expression is correlated with poor survival in patients with invasive breast carcinoma. PLoS ONE 2017, 12, e0187635. [CrossRef]

63. Lambert, A.W.; Wong, C.K.; Ozturk, S.; Papageorgis, P.; Raghunathan, R.; Alekseyev, Y.O.; Gower, A.C.; Reinhard, B.M.; Abdolmaleky, H.M.; Thiagalingam, S. Tumor cell-derived periostin regulates cytokines that maintain breast cancer stem cells. Mol. Cancer Res. 2016, 14, 103-113. [CrossRef]

64. Li, C.; Xu, J.; Wang, Q.; Geng, S.; Yan, Z.; You, J.; Li, Z.; Zou, X. Prognostic value of periostin in early-stage breast cancer treated with conserving surgery and radiotherapy. Oncol. Lett. 2018, 15, 8072-8078. [CrossRef] [PubMed]

65. Dong, N.; Zhang, L.; Jia, L.; Ji, W.; Wang, Z.; Ren, L.; Niu, R.; Zhou, Y. Identification of serum periostin as a potential diagnostic and prognostic marker for colorectal cancer. Clin. Lab. 2018, 64, 973-981. [CrossRef] [PubMed]

66. Jang, S.Y.; Park, S.Y.; Lee, H.W.; Choi, Y.-K.; Park, K.-G.; Yoon, G.S.; Tak, W.Y.; Kweon, Y.O.; Hur, K.; Lee, W.K. The combination of periostin overexpression and microvascular invasion is related to a poor prognosis for hepatocellular carcinoma. Gut Liver 2016, 10, 948-954. [CrossRef] [PubMed]

67. Cattrini, C.; Rubagotti, A.; Nuzzo, P.V.; Zinoli, L.; Salvi, S.; Boccardo, S.; Perachino, M.; Cerbone, L.; Vallome, G.; Latocca, M.M.; et al. Overexpression of periostin in tumor biopsy samples is associated with prostate cancer phenotype and clinical outcome. Clin. Genitourin. Cancer 2018, 16, e1257-e1265. [CrossRef] [PubMed]

68. Hong, L.-Z.; Wei, X.-W.; Chen, J.-F.; Shi, Y. Overexpression of periostin predicts poor prognosis in non-small cell lung cancer. Oncol. Lett. 2013, 6, 1595-1603. [CrossRef]

69. Oh, H.J.; Bae, J.M.; Wen, X.-Y.; Cho, N.-Y.; Kim, J.H.; Kang, G.H. Overexpression of POSTN in Tumor Stroma Is a Poor Prognostic Indicator of Colorectal Cancer. J. Pathol. Transl. Med. 2017, 51, 306-313. [CrossRef]

70. Silvers, C.R.; Liu, Y.-R.; Wu, C.-H.; Miyamoto, H.; Messing, E.M.; Lee, Y.-F. Identification of extracellular vesicle-borne periostin as a feature of muscle-invasive bladder cancer. Oncotarget 2016, 7, 23335-23345. [CrossRef]

71. Riener, M.-O.; Fritzsche, F.R.; Soll, C.; Pestalozzi, B.C.; Probst-Hensch, N.; Clavien, P.-A.; Jochum, W.; Soltermann, A.; Moch, H.; Kristiansen, G. Expression of the extracellular matrix protein periostin in liver tumours and bile duct carcinomas. Histopathology 2010, 56, 600-606. [CrossRef]

72. Kiely, M.; Hodgins, S.J.; Merrigan, B.A.; Tormey, S.; Kiely, P.A.; O'Connor, E.M. Real-time cell analysis of the inhibitory effect of vitamin K2 on adhesion and proliferation of breast cancer cells. Nutr. Res. 2015, 35, 736-743. [CrossRef]

73. Refolo, M.G.; D’Alessandro, R.; Lippolis, C.; Carella, N.; Cavallini, A.; Messa, C.; Carr, B.I. IGF-1R tyrosine kinase inhibitors and Vitamin K1 enhance the antitumor effects of Regorafenib in HCC cell lines. Oncotarget 2017, 8, 103465-103476. [CrossRef] 
74. Dahlberg, S.; Ede, J.; Schött, U. Vitamin K and cancer. Scand. J. Clin. Lab. Investig. 2017, 77, 555-567. [CrossRef] [PubMed]

75. Nimptsch, K.; Rohrmann, S.; Kaaks, R.; Linseisen, J. Dietary vitamin K intake in relation to cancer incidence and mortality: Results from the Heidelberg cohort of the European Prospective Investigation into Cancer and Nutrition (EPIC-Heidelberg). Am. J. Clin. Nutr. 2010, 91, 1348-1358. [CrossRef] [PubMed]

76. Juanola-Falgarona, M.; Salas-Salvadó, J.; Martínez-González, M.A.; Corella, D.; Estruch, R.; Ros, E.; Fitó, M.; Arós, F.; Gomez-Gracia, E.; Fiol, M.; et al. Dietary intake of vitamin k is inversely associated with mortality risk. J. Nutr. 2014, 144, 743-750. [CrossRef] [PubMed]

77. Yoshida, H.; Shiratori, Y.; Kudo, M.; Shiina, S.; Mizuta, T.; Kojiro, M.; Yamamoto, K.; Koike, Y.; Saito, K.; Koyanagi, N.; et al. Effect of vitamin K2 on the recurrence of hepatocellular carcinoma. Hepatology 2011, 54, 532-540. [CrossRef] [PubMed]

78. Bin Riaz, I.; Riaz, H.; Riaz, T.; Rahman, S.; Amir, M.; Badshah, M.B.; Kazi, A.N. Role of vitamin K2 in preventing the recurrence of hepatocellular carcinoma after curative treatment: A meta-analysis of randomized controlled trials. BMC Gastroenterol. 2012, 12, 170. [CrossRef]

79. Habu, D.; Shiomi, S.; Tamori, A.; Takeda, T.; Tanaka, T.; Kubo, S.; Nishiguchi, S. Role of Vitamin K2 in the Development of hepatocellular carcinoma in women with viral cirrhosis of the liver. JAMA 2004, 292, 358-361. [CrossRef]

(C) 2020 by the authors. Licensee MDPI, Basel, Switzerland. This article is an open access article distributed under the terms and conditions of the Creative Commons Attribution (CC BY) license (http://creativecommons.org/licenses/by/4.0/). 